\title{
Influence of Strength, Sprint Running, and Combined Strength and Sprint Running Training on Short Sprint Performance in Young Adults
}

\author{
Authors \\ M. C. Marques ${ }^{1,2}$, T. J. Gabbett ${ }^{3,4}$, D. A. Marinho", ${ }^{1,2}$ A. J. Blazevich ${ }^{5}$, A. Sousa ${ }^{1}$, R. van den Tillaar 6 , \\ M. Izquierdo \\ Affiliations \\ Affiliation addresses are listed at the end of the article
}

\author{
Key words \\ - velocity \\ - sprint \\ - full-squat \\ - transfer \\ - combined training
}

accepted after revision February 10, 2015

Bibliography DOI http://dx.doi.org/ 10.1055/s-0035-1547284 Published online:

May 6, 2015

Int J Sports Med 2015; 36: 789-795 @ Georg Thieme Verlag KG Stuttgart · New York ISSN 0172-4622

\section{Correspondence}

\section{Mikel Izquierdo, PhD}

Department of Health Sciences Public University of Navarra

Campus of Tudela

Av. de Tarazona s/n. 31500

Tudela (Navarra)

Spain

Tel.: + 34/948/417 876

Fax: + 34/948/169 169

mikel.izquierdo@gmail.com

\section{Abstract}

$\nabla$

The purpose of this study was to assess the degree of transference of 6 weeks of full squat vs. full squat plus sprint running training to short (ranged from $0-10$ to $0-30 \mathrm{~m}$ ) sprint running performance in non-athletes. We hypothesized that a speed-full-squat training regimen could enhance squat strength and power with simultaneous improvements in short sprint performance. 122 physically active adults (age: $20.5 \pm 2.5$ years; body mass: $65.8 \pm 6.1 \mathrm{~kg}$; height: $1.71 \pm 0.08 \mathrm{~m}$ ) were randomly divided into 4 groups: full squat training $(n=36)$, combined full squat and sprint

\section{Introduction}

\section{$\nabla$}

Running capacity can be developed through a myriad of training methods $[3,4,7,19,23,32]$ including traditional heavy-resistance training, ballistic and non-ballistic resistance training as well as sprint running training and running drills. In particular, high-intensity lower-body strength training improves muscular strength about the hip, knee, and ankle joints, and some researchers have reported increases in acceleration rates and maximum velocity during sprint running $[3,6,7]$. Yet, research has reported inconsistent results in relation to the effect of strength training on sprint running performance $[9,11,31]$. These conflicting results may be due to the fact that sprint running involves multiple-joint motions with a precise co-ordination between various muscle groups that is not adequately assessed by single-joint tests that isolate muscles $[8,9,33]$. Thus, a combination of strength and sprint-specific training is probably needed for an optimal performance adaptation to occur.

However, this approach to training is problematic in non-professional (i.e., non-elite) athletes who typically devote only small amounts of time to training when compared to elite athletes but still training $(\mathrm{n}=32)$, speed training only $(\mathrm{n}=34)$ and non-training control group $(n=20)$. Each training group completed 2 sessions per week over 6 weeks, while the control group performed only their normal physical activity. Sprint performance was improved after sprint running or full squat training alone $(1.7 \%$ and $1.8 \% \mathrm{P}<0.05$, respectively), however larger enhancements (2.3\%; $\mathrm{P}<0.01)$ were observed after the combined full squat plus sprint training intervention. These results suggest that in recreationally active adults, combined full squat and sprint training provides a greater stimulus for improving sprint performance than either modality alone.

aim to achieve notable improvements in running ability to compete successfully in their sport. Importantly, non-elite athletes often receive no feedback during their sprint running training sessions, so it is not known whether these sessions sufficiently improve running technique and thus lead to a performance benefit. Alternatively, the practice of sprint running technique might be vital in non-elite athletes, and the addition of strength training might be considered of secondary importance. The possibility exists, therefore, that the addition of multiple forms of training (e.g., traditional strength training plus sprint running training) may provide minimal benefit to performing either strength or sprint training alone in this population. To the best of our knowledge, few studies have described the transfer of training effects from different strength training regimens that include standard strength training exercises to the acceleration phases of a sprint run when performed with or without additional sprint running training $[3,6]$. Findings from the small number of studies in the literature regarding the effects of combined training methods on jumping and sprinting in non-elite populations have also been inconclusive [16,19,21-24]. 
Uusing a multi-joint exercise such as the full-squat should be advantageous when exploring relationships with sprinting because it seems to mimic the triple-extension pattern required in the acceleration phase of the sprint run [27]. Sáez de Villarreal and colleagues [24] compared the effects of 5 different training stimuli on sprint running capacity and muscular force production in active, but not well trained, adults. A combined training approach using full-squat and parallel-squat exercises with loaded jumping and plyometric training resulted in improvements in maximal strength and vertical velocity in the squat lift but no significant change in sprint running performance. The authors [24] suggested that the similarity between movement patterns as well as the velocity of displacement common to the training and testing methods may have contributed to greater specific performance improvements. Hence, lack of specificity to sprint running in these exercises may well have been responsible for the absence or small improvements in sprint times. Neverthlesss, the combination of specific biomechanical stimuli with a single strength (e.g., full squat) exercise requires further exploration $[21,30]$. However, to our best knowledge, no studies have compared the effectiveness of a full-squat training only regimen, a sprint training program and a combination of both approaches in order to improve short sprint performance.

The purpose of the current study was twofold: (i) to examine the effects of 6 weeks of distinct strength and sprint running training programs on short sprint capacity, and (ii) to assess the degree of transference of the full-squat exercise to sprint running performance in physcially active but non-elite individuals. It was our hypothesis that the combined training approach (i.e., using full-squat plus sprint running training) would contribute to greater improvements in strength, power and short sprint running performance than strength or sprint training alone.

\section{Material \& Methods}

$\nabla$

122 male $(n=85)$ and female $(n=37)$ active subjects (age: $20.5 \pm 2.5$ years; body mass: $65.8 \pm 6.1 \mathrm{~kg}$; height: $1.71 \pm 0.08 \mathrm{~m}$ ) were divided into 4 groups: full-squat training $(n=36)$, combined full - squat and sprint training $(n=32)$, sprint training only $(n=34)$, and control (non-training) group $(n=20)$. All participants were trained amateur athletes of different sports (e.g., soccer, futsal, track and field, and team handball). Consequently, all the participants were well conditioned, and all could squat 2 times their body mass. Before commencing the study, subjects had a physical examination, and each was cleared of any medical disorders that might limit full participation in the investigation. Subjects were required to sign an informed consent form before the experiment. 4 subjects were excluded from the analysis after drop-out from the study due to personal reasons (3 subjects from the sprint-full squat training group, and one from the sprint training group). At baseline, no differences between groups were observed in anthropometric characteristics or strength, power or sprint running performances. The full-squat training group completed 2 training sessions per week over 6 weeks, while the sprint training group performed a twiceweekly sprint training regimen over the same period. The sprintfull squat training group performed both full squat and sprint running exercises. Subjects completed 2 full squat and 2 sprint running sessions per week, although each session only comprised half of the training volume of the other groups so that the total training volume was matched between the groups. Sub- jects performed half of the training sets in each session and adjustments were made when necessary, attempting to match the same training volume. Moreover, each session was designed to be similar to what would normally be performed in specific session training. Session RPEs were taken during pilot testing and minor adjustments were made in order to equate the sessions by RPEs. The control group did not undergo any specific orientated physical activity. The experimental procedures were approved by the local ethical committee and followed the Helsinki declaration. The study also meets the ethical standards of the journal as described in the Harriss and Atkinson [13] update.

\section{Overview}

All testing procedures were applied to all groups before the experimental period (pre-training test) and after 6 weeks of training (post-training test). Testing was completed in 2 sessions separated by a day of rest, always at the same location and supervised by the same researchers. In the first session, anthropometric assessments were completed (body mass and height) and sprint running performance was tested. In the second session (2 days later) strength (full-squat) testing was completed. Before testing, each subject was familiarized with the sprint running or strength testing procedures, and completed a general warm-up routine (described below). Verbal encouragement was given throughout the tests and feedback of performance was provided in order to maximize motivation.

\section{Anthropometric testing}

Height $(\mathrm{m})$ and body mass $(\mathrm{kg})$ were assessed according to international standards for anthropometric assessment [15]. Height was assessed using a stadiometer (SECA, model 225, Germany) with a scale range of $0.1 \mathrm{~cm}$. Body mass was measured to the nearest $0.1 \mathrm{~kg}$ using a digital scale (Philips, type HF 351/00, Germany).

\section{Strength and power testing}

Participants performed a full squat assuming an extended position starting from the knee angle of $\sim 180^{\circ}$, with shoulders in contact with a bar. Each participant descended in a continuous motion until the top of the thighs was below the horizontal plane, then immediately reversed motion and ascended back to the upright position. Feedback of the eccentric distance travelled and concentric velocity were provided. This was accomplished by using a linear velocity transducer (described elsewhere in detail [26]) that registered the kinematics of every repetition and whose software provided visual and auditory feedback in real-time. Unlike the eccentric phase that was performed at a controlled mean velocity (i.e., approximately $0.5 \mathrm{~m} \cdot \mathrm{s}^{-1}$ ), athletes were required to always execute the concentric phase of each repetition at maximal intended velocity; that is, explosively.

The trunk was kept as straight as possible. A safety belt was used by all participants. The tests were performed in a squatting apparatus (Smith machine, Model Adan Sport, Set 0.04. Spain). Warm-up consisted of a set of ten repetitions at a load of 40-60\% of the perceived maximum. The last acceptable extension with highest possible load was determined as 1-RM. The rest period between sets was $2 \mathrm{~min}$. Velocity of displacement during the concentric phase of the full squat $\left(\mathrm{m} \cdot \mathrm{s}^{-1}\right)$ was determined by adjusting the added load until the highest velocity was obtained. Velocity index was calculated as an average value of the peak velocity obtained with all the loads. The bar weight was then 
progressively increased in $10 \mathrm{~kg}$ increments for each set (i.e., bar only; bar $+10 \mathrm{~kg}$; bar $+20 \mathrm{~kg}$, until the highest possible load) with 2 trials executed with each weight. Warm-up consisted of a set of 5 repetitions with the weight of the bar $(17 \mathrm{~kg})$. Velocity of displacement was determined using a squatting apparatus in which the barbell was attached at both ends, with linear bearings on 2 vertical bars allowing only vertical movements. Further, bar displacement, and peak, and mean velocity $\left(\mathrm{m} \cdot \mathrm{s}^{-1}\right)$ were recorded using a distance encoder attached to one end of the bar. The distance encoder recorded the position and direction of the bar to an accuracy of $0.0003 \mathrm{~m}$. A computer program (Isocontrol Dinámico, Version 3.6. JLML, Spain) was used to calculate the velocity of displacement for each repetition of full squat performed throughout the whole range of motion. Adequate recovery was allowed between all trials $(2-3 \mathrm{~min})$. The best trial with each weight was recorded for the subsequent statistical analysis. Further, the optimal power output was calculated for training purposes. The training program was individualized for each participant based on the calculation of the load that they moved at $1 \mathrm{~m} \cdot \mathrm{s}^{-1}$. This value was chosen for 2 main reasons: a) the maximal load used in squat exercise during RT was the load that elicited $\sim 1 \mathrm{~m} \cdot \mathrm{s}^{-1}$, which represents approximately $56 \% 1 \mathrm{RM}$ [2], thereby providing enough information to schedule the training; $\mathrm{b}$ ) larger loads may predispose to a higher risk of ventral flexion of the lumbar spine while squatting [20].

\section{Sprint running testing}

This test was performed on an athletics track, under the direct supervision of the investigators at the same time of day $( \pm 1 \mathrm{~h})$ for each subject and under constant environmental conditions $\left(\sim 21^{\circ} \mathrm{C}, \sim 50 \%\right.$ humidity). For sprint testing, subjects performed 3 maximum effort sprints over $30 \mathrm{~m}$. Times to 10,20 and $30 \mathrm{~m}$ were recorded using Brower photocells (Wireless Sprint System, USA). Subjects performed sprint trials separated by 3 min of passive rest and the average of the best 2 sprints was considered. The intraclass correlation coefficient (ICC) for times to $30 \mathrm{~m}$ was 0.95 (95\% confidence interval: $0.91-0.97$ ) and the CV was $3.4 \%$.

\section{Training programs}

The training programs completed by each group are shown in $\odot$ Table 1. All training sessions were fully supervised and training diaries were maintained for each subject. The subjects were instructed to maintain their normal daily activities throughout the 6-wk study, including participation in recreational sporting activities. The participants did not undertake any additional resistance training activities during the testing and training period. Rest intervals of $3 \mathrm{~min}$ between sets were employed. The program was conducted every Tuesday and Friday (5:00 p.m). Each strength training session lasted for approximately 20 min including the warm-up period. The training program was individualized for each participant based on the calculation of the load that they moved at $1 \mathrm{~m} \cdot \mathrm{s}^{-1}$. This was chosen because this velocity has been observed to be the optimal to produce the maximal power output [24]. The sprint training was conducted after a 10- min warm up period and included 3-4 sets of $15-30 \mathrm{~m}$ sprint running (as shown in $\odot$ Table 2). Rest intervals of 3 min between sets were employed. Each sprint training session lasted for approximately $15 \mathrm{~min}$ including the warm-up period. The sprint-full squat training group performed combined squat and sprint running exercises. The control group did not follow a special training program ( $\bullet$ Table 3 ).
Table 1 Squat training program employed between week 1 and week 6.

\begin{tabular}{|c|c|c|c|c|c|}
\hline Weeks & Sessions & $\begin{array}{l}\text { Warm-up } \\
\text { sets * }\end{array}$ & $\begin{array}{l}\text { Load } \\
\text { (Intensity) ** }^{*}\end{array}$ & Sets $\times$ Reps. & $\begin{array}{l}\text { Rest be- } \\
\text { tween sets }\end{array}$ \\
\hline \multirow[t]{2}{*}{1} & 1 & $1 \times 8+1 \times 8$ & $80 \%$ & $2 \times 8$ & $120 s$ \\
\hline & 2 & $1 \times 8+1 \times 8$ & $80 \%$ & $3 \times 8$ & $120 s$ \\
\hline \multirow[t]{2}{*}{2} & 3 & $1 \times 8+1 \times 8$ & $85 \%$ & $3 \times 8$ & $120 \mathrm{~s}$ \\
\hline & 4 & $1 \times 8+1 \times 8$ & $85 \%$ & $4 \times 6$ & $120 \mathrm{~s}$ \\
\hline \multirow[t]{2}{*}{3} & 5 & $1 \times 8+1 \times 8$ & $90 \%$ & $3 \times 6$ & $120 \mathrm{~s}$ \\
\hline & 6 & $1 \times 8+1 \times 8$ & $90 \%$ & $3 \times 8$ & $120 s$ \\
\hline \multirow[t]{2}{*}{4} & 7 & $1 \times 8+1 \times 6$ & $95 \%$ & $3 \times 6$ & $180 \mathrm{~s}$ \\
\hline & 8 & $1 \times 8+1 \times 6$ & $95 \%$ & $4 \times 5$ & $180 \mathrm{~s}$ \\
\hline \multirow[t]{2}{*}{5} & 9 & $1 \times 8+1 \times 6$ & $100 \%$ & $3 \times 6$ & $180 \mathrm{~s}$ \\
\hline & 10 & $1 \times 8+1 \times 6$ & $100 \%$ & $4 \times 5$ & $180 \mathrm{~s}$ \\
\hline \multirow[t]{2}{*}{6} & 11 & $1 \times 8+1 \times 6$ & $90 \%$ & $3 \times 6$ & $120 \mathrm{~s}$ \\
\hline & 12 & $1 \times 8+1 \times 6$ & $80 \%$ & $3 \times 8$ & $120 \mathrm{~s}$ \\
\hline
\end{tabular}

Table 2 Sprint training program employed between week 1 and week 6.

\begin{tabular}{|c|c|c|c|c|c|}
\hline Weeks & Sessions & $\begin{array}{l}\text { Warm-up } \\
\text { sets* }\end{array}$ & Intensity ** & Series $\times$ Reps & $\begin{array}{l}\text { Rest be- } \\
\text { tween sets }\end{array}$ \\
\hline \multirow[t]{2}{*}{1} & 1 & $3 \times 20 m$ & \multirow{12}{*}{ Maximum } & $3 \times 15 \mathrm{~m}$ & $120 s$ \\
\hline & 2 & $3 \times 20 \mathrm{~m}$ & & $4 \times 15 m$ & $120 s$ \\
\hline \multirow[t]{2}{*}{2} & 3 & $3 \times 25 \mathrm{~m}$ & & $3 \times 20 m$ & $120 \mathrm{~s}$ \\
\hline & 4 & $3 \times 25 m$ & & $4 \times 20 m$ & $120 s$ \\
\hline \multirow[t]{2}{*}{3} & 5 & $3 \times 30 \mathrm{~m}$ & & $3 \times 25 \mathrm{~m}$ & $150 \mathrm{~s}$ \\
\hline & 6 & $3 \times 30 m$ & & $4 \times 25 m$ & $150 s$ \\
\hline \multirow[t]{2}{*}{4} & 7 & $3 \times 35 \mathrm{~m}$ & & $3 \times 30 \mathrm{~m}$ & $180 \mathrm{~s}$ \\
\hline & 8 & $3 \times 35 \mathrm{~m}$ & & $4 \times 30 m$ & $180 \mathrm{~s}$ \\
\hline \multirow[t]{2}{*}{5} & 9 & $3 \times 25 \mathrm{~m}$ & & $4 \times 20 m$ & $150 \mathrm{~s}$ \\
\hline & 10 & $3 \times 25 \mathrm{~m}$ & & $5 \times 20 m$ & $150 s$ \\
\hline \multirow[t]{2}{*}{6} & 11 & $3 \times 30 m$ & & $4 \times 25 m$ & $180 \mathrm{~s}$ \\
\hline & 12 & $3 \times 30 \mathrm{~m}$ & & $2 \times 25 \mathrm{~m}$ & $180 \mathrm{~s}$ \\
\hline
\end{tabular}

\section{Statistical analysis}

A one-way ANOVA was used to examine potential betweengroup differences in anthropometry, strength (1-RM), power (load lifted at $1 \mathrm{~m} \cdot \mathrm{s}^{-1}$ ) and sprint running times prior to training. To compare the effects of the training protocols, a mixed design 2 (test occasion: pre-post training, repeated measures) $\times 4$ (training group) analysis of variance (ANOVA) for each performance test was used. To evaluate the performance changes within training groups a one-way ANOVA with repeated measures (pre-post test) for each exercise was performed. The level of significance was set at $\mathrm{p} \leq 0.05$.

\section{Results \\ $\nabla$}

A decrease in sprint running times at $10 \mathrm{~m}(\mathrm{p}<0.05), 20 \mathrm{~m}$ $(p<0.001)$ and $30 \mathrm{~m}(\mathrm{p}<0.001)$ as well as an increase in 1-RM load and load displaced at $1 \mathrm{~m} \cdot \mathrm{s}^{-1}(\boldsymbol{\bullet}$ Fig. 1,2) was found after the 6-wk training period in all 3 training groups. Oneway ANOVA showed that the times at 20 and $30 \mathrm{~m}$ decreased significantly in every training group, while for the $10 \mathrm{~m}$ times a significant decrease in time was only found for the combination sprint-full 
Table 3 Combined training program employed between week 1 and week 6 .

\begin{tabular}{|c|c|c|c|c|c|c|c|c|c|}
\hline \multirow[b]{2}{*}{ Weeks } & \multirow[b]{2}{*}{ Sessions } & \multicolumn{2}{|c|}{ Warm-up sets } & \multicolumn{2}{|c|}{ Intensity } & \multicolumn{2}{|c|}{ Series $\times$ Reps. } & \multicolumn{2}{|c|}{ Rest between sets } \\
\hline & & Sprint * & Squat ${ }^{* *}$ & Sprint $\dagger$ & Squat $+\dagger$ & Sprint & Squat & Sprint & Squat \\
\hline \multirow[t]{2}{*}{1} & 1 & $3 \times 20 m$ & $1 \times 8+1 \times 8$ & \multirow{12}{*}{ Maximum } & $80 \%$ & $2 \times 15 \mathrm{~m}$ & $1 \times 8$ & $120 s$ & $120 \mathrm{~s}$ \\
\hline & 2 & $3 \times 20 m$ & $1 \times 8+1 \times 8$ & & $80 \%$ & $2 \times 15 \mathrm{~m}$ & $2 \times 8$ & $120 s$ & $120 \mathrm{~s}$ \\
\hline \multirow[t]{2}{*}{2} & 3 & $3 \times 25 \mathrm{~m}$ & $1 \times 8+1 \times 8$ & & $85 \%$ & $2 \times 20 m$ & $1 \times 8$ & $120 s$ & $120 \mathrm{~s}$ \\
\hline & 4 & $3 \times 25 \mathrm{~m}$ & $1 \times 8+1 \times 8$ & & $85 \%$ & $2 \times 20 m$ & $2 \times 6$ & $120 s$ & $120 s$ \\
\hline \multirow[t]{2}{*}{3} & 5 & $3 \times 30 m$ & $1 \times 8+1 \times 8$ & & $90 \%$ & $2 \times 25 m$ & $1 \times 6$ & $150 s$ & $120 \mathrm{~s}$ \\
\hline & 6 & $3 \times 30 \mathrm{~m}$ & $1 \times 8+1 \times 8$ & & $90 \%$ & $2 \times 25 m$ & $2 \times 8$ & $150 s$ & $120 \mathrm{~s}$ \\
\hline \multirow[t]{2}{*}{4} & 7 & $3 \times 35 \mathrm{~m}$ & $1 \times 8+1 \times 6$ & & $95 \%$ & $2 \times 30 m$ & $1 \times 6$ & $180 \mathrm{~s}$ & $180 \mathrm{~s}$ \\
\hline & 8 & $3 \times 35 \mathrm{~m}$ & $1 \times 8+1 \times 6$ & & $95 \%$ & $2 \times 30 m$ & $2 \times 5$ & $180 \mathrm{~s}$ & $180 \mathrm{~s}$ \\
\hline \multirow[t]{2}{*}{5} & 9 & $3 \times 25 m$ & $1 \times 8+1 \times 6$ & & $100 \%$ & $2 \times 20 m$ & $2 \times 6$ & $150 s$ & $180 \mathrm{~s}$ \\
\hline & 10 & $3 \times 25 \mathrm{~m}$ & $1 \times 8+1 \times 6$ & & $100 \%$ & $2 \times 20 m$ & $2 \times 5$ & $150 s$ & $180 \mathrm{~s}$ \\
\hline \multirow[t]{2}{*}{6} & 11 & $3 \times 30 \mathrm{~m}$ & $1 \times 8+1 \times 6$ & & $90 \%$ & $1 \times 25 m$ & $2 \times 6$ & $180 \mathrm{~s}$ & $120 \mathrm{~s}$ \\
\hline & 12 & $3 \times 30 \mathrm{~m}$ & $1 \times 8+1 \times 6$ & & $80 \%$ & $1 \times 25 m$ & $1 \times 8$ & $180 \mathrm{~s}$ & $120 \mathrm{~s}$ \\
\hline
\end{tabular}

\section{Warm-up sets}

* - subjects performed sprints in which gradually increasing speed until they reach the maximum speed

** -subjects performed the warm-up with lighter loads to those in training

Intensity

$\dagger$-subjects always performed sprints at full speed

† - the load is defined based on the percentage of the load that a subject is able to displace the propulsive an average speed of $1 \mathrm{~m} \cdot \mathrm{s}^{-1}$

Note: sprint training took place before squat training with a rest of $10 \mathrm{~min}$ between both training regimens

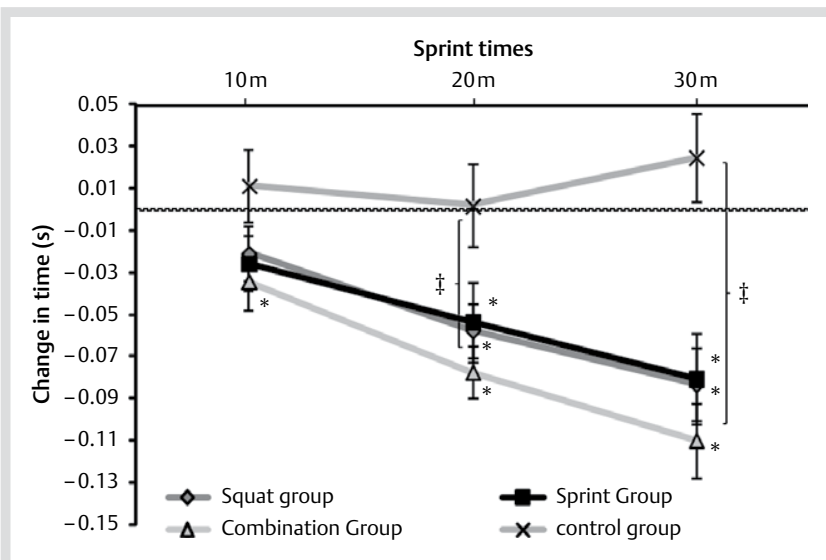

Fig. 1 Changes in 10, 20 and $30 \mathrm{~m}$ sprint time from pre- to post-training (mean \pm SEM) for each training group (full squat, sprint, sprint-full squat and control). ${ }^{*}$ indicates a significant difference $(p<0.05)$ in the change in time from the pre- to post-training. $\ddagger$ indicates a significant difference $(p<0.05)$ in the change between the control group and all other groups.

squat training group ( $\odot$ Fig. 1). A between group effect was found for all variables $(\mathrm{p}<0.05)$, except $10 \mathrm{~m}$ sprint time $(p=0.235)$. A post-hoc comparison showed that the full squat and sprint-full squat training programs resulted in greater overall increases in $1-\mathrm{RM}(\mathrm{p}<0.05)$ than the other 2 groups, but there was no difference between the full squat and sprint-full squat groups. The load displaced at $1 \mathrm{~m} \cdot \mathrm{s}^{-1}$ during the full-squat exercise also increased more after the 6-wk intervention for the full squat and sprint-full squat training groups compared with the control group ( $\odot$ Fig. 2 ).

\section{Discussion}

The major finding of the current study was that short distance (ranging from 0-10 to $0-30 \mathrm{~m}$ ) sprint running performance of physically active adults was significantly improved after completing only 12 sessions of training, even when no sprint specific

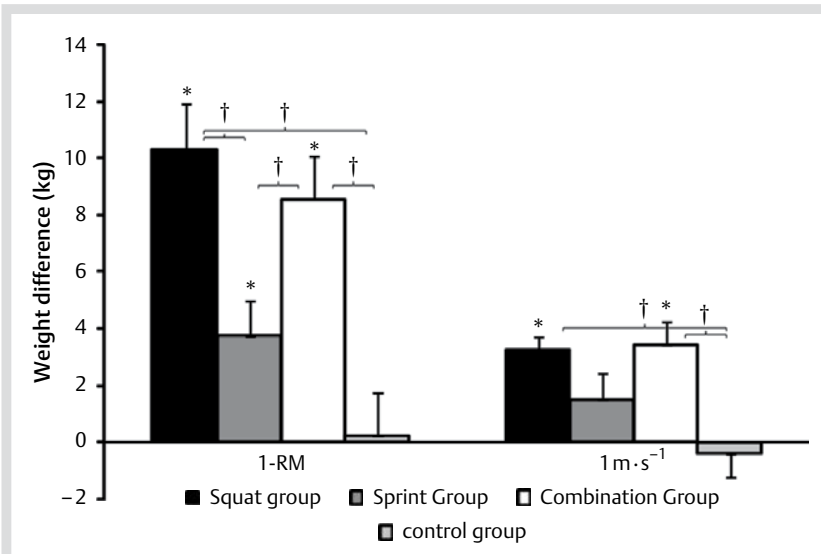

Fig. 2 Pre- to post-training changes (mean \pm SEM) in 1-RM squat and load lifted at $1 \mathrm{~m} \cdot \mathrm{s}^{-1}$ in each training group (full squat, sprint, sprint-full squat and control). ${ }^{*}$ indicates a significant difference $(p<0.05)$ in load lifted from pre - to post-training. $\dagger$ indicates a significant difference $(p<0.05)$ in load lifted between 2 groups.

training was performed. Nonetheless, improvements in squat strength (1-RM), squat power (load lifted at $1 \mathrm{~m} \cdot \mathrm{s}^{-1}$ ) and sprint running performance were more pronounced when the strength (full squat) training was combined with a sprint running training program. These results provide additional support to the hypothesis that combined training routines should be favoured over single-element training programs for the improvement of short-distance sprint running performance in active but nonelite individuals. These findings are important for recreational athletes, who form the majority of sporting participants; the current research is thus of immediate practical importance to the larger/broader sporting population.

The independent and/or combined effects of strength and plyometric training programs on physical performance have been examined previously [2,20,21], yet improvements in maximal strength alone appear to be insufficient to improve power and sprint performance $[7,8,33]$. There seems to be a requirement to combine strength training with other exercises in order to 
obtain significant improvements in muscle power and sprint performance [1]. The current findings are in agreement with others who have reported improvements in sprint performance after both combined strength training and plyometric training and heavy-resistance training alone $[1,6]$, however we provide new information showing that when only a single mode of training is performed, strength training can provide the same running performance benefit as sprint-specific training in active, non-elite individuals. In contrast, Saez de Villarreal et al. [24] failed to observe improvements in short-distance sprint performance $(0-15$ and $0-30 \mathrm{~m})$ in any experimental group performing full-squat, parallel-squat, loaded countermovement jumping or plyometric training. Such results are in agreement with other studies where the performance of unloaded plyometric exercises did not induce a significant change in $20-\mathrm{m}$ [22] or $30-\mathrm{m}$ [10] sprint times in strength-trained subjects. The small improvement in sprint performance in the study of Saez de Villarreal et al. [24] could be attributed to the lack of specificity in the training [33]. Thus, it may be hypothesized that training programs that incorporate sprint-specific training (i.e., skipping, jumps with maximal horizontal displacement), particularly when combined with strength/power training, may provide more beneficial effects $[1,15]$.

Finally, we must evidence the fact that the combined training induced similar strength and sprint improvements even though performing half of the specific volume of each training regimen, although the total volume was equal. This means that the load intensity was the main parameter influencing both strength and sprint running improvements using a RT program with moderate load and a low number of repetitions per set. Further, this also indicates that using movement velocity to monitor and individualize the strength load for training might be of greater use than other methods that cause greater stress. In this respect, most studies using isoinertial training in young athletes have commonly used 'repetitions per set to muscular failure' or' high intensities' (70-95\% 1-RM) in order to improve strength and muscular power $[15,16]$. In the current study, 2 researchers were present to supervise each workout session where the subjects were instructed to lift the load at maximum intended velocity in every repetition. Lifting the load at maximal velocity seems to be a key factor to optimize adaptations induced by RT. Performance in most competitive activities such as jumping, throwing and sprint running depend on the athlete's ability to produce force rapidly $[12,14,18,33]$. It has been shown that a major stimulus for the development of muscular power is the conscious effort to produce fast, explosive contractions, regardless of external resistance [5]. Several research groups have shown the effectiveness of power-oriented and heavy-resistance training in improving strength and physical abilities $[6,17,33]$. The current results concur with studies $[1,31]$ showing that a combined program, or strength training alone, can increase both strength and sprint performance. Of interest is that the magnitude of improvement in sprint performance was almost the same for the full squat-only and sprint training groups; the result suggests that strength training might be equally effective as sprint training when only a single form of training can be completed in active, non-elite individuals. However, caution must be taken when comparing the present results with the majority of previous studies conducted in athletes, as it is likely that athletic populations will have a prolonged history of training and greater training frequency, and will therefore adapt differently to specific types of training.
The present training programs resulted in similar enhancement in all training groups in $10 \mathrm{~m}$ sprint performance, although statistical significance was only observed in the sprint-full squat training group. This particular performance metric is highly dependent on acceleration capacity/power development $[25,28]$ as well as reaction time [25]. Chelly et al. [3] reported that 2 months of strength training performed twice a week induced enhancements of the first steps and $5 \mathrm{~m}$ sprint performance measured through a kinematic video analysis. Delecluse et al. [7] also reported that 9 weeks of high intensity strength training involving mixed lower limb exercises performed 3 times a week improved $10 \mathrm{~m}$ sprint performance in physically active subjects. However, conflicting evidence exists regarding the possibility of enhancing sprint running performance after a heavy strength training regimen $[17,29,31,33]$. This could be also associated with a possible low transfer of strength gains to sprint performance due to the low training specificity $[20,33]$. The present results, however, clearly show a benefit of strength training combined with sprint training in active, non-elite individuals when compared to sprint training only.

In relation to sprint training, no improvements were identified in $10 \mathrm{~m}$ sprint time in the sprint training-only group, which was in contrast to our initial hypothesis. In fact, a sprint training-only group was included in the present study in order to study the effect of highly specific motor pattern training on task (i.e., sprint running) performance. It makes sense that this task-specific practice would be sufficient to induce sprint performance enhancements in all phases of the $30 \mathrm{~m}$ sprint test in the current subjects, yet no change was observed in $10 \mathrm{~m}$ sprint results. One explanation for this result is that no specific sprint running technique feedback was given to the subjects, so significant improvements in movement patterns might not have been realized. It is not clear in previous studies whether specific instructions were given during training, and this is an important point of consideration for future studies. It is also important in a practical context because many non-elite athletes perform training without direct coaching feedback. In these scenarios, less benefit might be derived from these sessions than expected. It is also possible that a training duration of only 6 weeks with a frequency of 2 times a week might be insufficient for developing neuromuscular gains and creating a positive chronic adaptation of the specific motor skills that are crucial for enhancing $10 \mathrm{~m}$ sprint performance in previously non-sprint-trained individuals $[8,28,33]$. The total number of sessions completed might therefore be a factor investigated in future research. The sprint training program did not stimulate sufficient neuromuscular development (load displaced at $1 \mathrm{~m} \cdot \mathrm{s}^{-1} ; \mathrm{p}<0.05$ ) and $10 \mathrm{~m}$ sprint phase, but clearly had a positive effect in the sprint performance at 20 and $30 \mathrm{~m}$ in all groups tested.

In general, the findings of the present study provide evidence supporting the potential benefit of heavy, full squat strength training combined with a sprint training regimen for short-distance sprint running performance (i.e., $\leq 30 \mathrm{~m}$ ) in physcially active adults. Combined training strategies such as high-intensity resistance training followed by a maximal velocity sprint running training regimen can enhance muscular strength, power and skill-based activities such as sprint running. $[18,20,29,33]$ The present results suggest that such strategies are superior to programs incorporating only strength or sprint running training alone in non-elite subjects.

While our results demonstrate improvements in sprinting speed in untrained subjects, it is unclear if similar improvements 
would occur in highly trained individuals or sprinters training for a specific track event (e.g., $100 \mathrm{~m}$ sprint). The current results demonstrated improvements in speed over $30 \mathrm{~m}$, yet it is well documented that in sprinters, maximal velocity over a $100 \mathrm{~m}$ sprint occurs at approximately $50-60 \mathrm{~m}$ [8]. As such, it is possible that if the prescribed training program was provided to sprinters, it may have improved acceleration but not maximal velocity. Furthermore, it is likely that additional technical skill training may be required to elicit further adaptations in sprinters.

\section{Conclusions}

In the present study, short-sprint performance was increased in physcially active subjects after a 6-wk strength training (full squat) or sprint running training regimen, however superior results (in $10 \mathrm{~m}$ time and in strength and power tests) were obtained when combined strength and sprint running training was performed. Moreover, the present results add to the current literature by indicating that the combination of strength training using the traditional full squat exercise combined with sprint training (where no coaching instruction was given) may be superior to strength or sprint training alone in active, but nonelite individuals. However, if the combined training cannot be performed, our results indicate that short-sprint running performance might be enhanced equally after strength training or specific sprint running practice, which has implications for program design in this population.

\section{Practical Implications}

$\nabla$

- Sprint performance can be improved with either full squat training or sprint running training in physically active subjects.

- However, greater improvements in sprint performance can be achieved by using a training program consisting of full squat and sprint training, than either modality in isolation.

\section{Acknowledgements \\ $\nabla$}

The authors would like to thank the important scientific contribution of Dr. Jason Vescovi from the Department of Kinesiology and Health Science, York University, Toronto, Ontario, Canada. This work was supported by University of Beira Interior and Santander Totta bank (UBI/FCSH/Santander/2010).

Conflict of interest: The authors have no conflict of interest to declare.

\footnotetext{
Affiliations

Department of Sports Sciences, University of Beira Interior, Covilhã, Portugal Research Centre for Sport, Health and Human Development, Vila Real, Portugal

School of Exercise Science, Australian Catholic University, Brisbane, Australia ${ }^{4}$ School of Human Movement Studies, The University of Queensland, Brisbane, Australia

Center for Exercise and Sports Science Research, Edith Cowan University, Joondalup, Australia

Nord Trøndelag University College, Levanger, Norway

Department of Health Sciences, Public University of Navarra, Pamplona, Spain
}

\section{References}

1 Adams K, O'Shea JP, O'Shea KL, Climstein M. The effect of six weeks of squat, plyometric and squat-plyometric training on power production. J Strength Cond Res 1992; 6: 36-41

2 Alvarez-San Emeterio C, Antunano NP, López-Sobaler AM, GonzálezBadillo JJ. Effect of strength training and the practice of Alpine skiing on bone mass density, growth, body composition, and the strength and power of the legs of adolescent skiers. J Strength Cond Res 2011; 25: 2879-2890

3 Chelly MS, Fathloun M, Cherif N, Ben Amar M, Tabka Z, Van Praagh E. Effects of a back squat training program on leg power, jump, and sprint performances in junior soccer players. J Strength Cond Res 2009; 23: 2241-2249

4 Chelly SM, Denis C. Leg power and hopping stiffness: relationship with sprint running performance. Med Sci Sports Exerc 2001; 33: 326-333

5 Chu DA. Explosive power \& strength: complex training for maximum results. Champaign, IL: Human Kinetics, 1996

6 Cormie P, McGuigan MR, Newton RU. Adaptations in athletic performance after ballistic power versus strength training. Med Sci Sports Exer 2010; 42: 1582-1598

7 Delecluse C, Van Coppenolle H, Willems E, Van Leemputte M, Diels $R$, Goris $M$. Influence of high-resistance and high-velocity training on sprint performance. Med Sci Sports Exerc 1995; 27: 1203-1209

8 Delecluse $C$. Influence of strength training on sprint running performance. Current findings and implications for training. Sports Med 1997; 24: 147-156

9 Dintiman GB. Effects of various training programs on running speed. Res Q Am Assoc Health, Phys Educ Recr 1964; 35: 456-463

10 Ebben WP, Watts PB. A review of combined weight training and plyometric training modes: complex training. Strength Cond J 1998; 20: $18-27$

11 Frost DM, Cronin J, Newton RU. A biomechanical evaluation of resistance: fundamental concepts for training and sports performance. Sports Med 2010; 40: 303-326

12 Harris GR, Stone MH, O'Bryant HS, Proulx CM, Johnson RL. Short-term performance effects of high power, high force, or combined weighttraining methods. J Strength Cond Res 2000; 14: 14-20

13 Harriss DJ, Atkinson G. Ethical standards in sport and exercise science research. Int J Sports Med 2013; 34: 1025-1028

14 Henry FM. Force-Time Characteristics of the Sprint Start. Res Q Am Assoc Health, Phys Educ Recr 1952; 23: 301-318

15 Izquierdo M, Hakkinen K, Gonzalez-Badillo JJ, Ibánez J, Gorostiaga EM. Effects of long-term training specificity on maximal strength and power of the upper and lower extremities in athletes from different sports. Eur J Appl Physiol 2002; 87: 264-271

16 Izquierdo M, Ibanez J, Gonzalez-Badillo JJ, Häkkinen K, Ratamess NA, Kraemer WJ, French DN, Eslava J, Altadill A, Asiain X, Gorostiaga EM. Differential effects of strength training leading to failure versus not to failure on hormonal responses, strength, and muscle power gains. J Appl Physiol 2006; 100: 1647-1656

17 John C, Gord S. Challenges in understanding the influence of maximal Power training on improving athletic performance. Sports Med 2005; 35: $213-234$

18 Kotzamanidis C, Chatzopoulos D, Michailidis C, Papaiakovou G, Patikas $D$. The effect of a combined high-intensity strength and speed training program on the running and jumping ability of soccer players. J Strength Cond Res 2005; 19: 369-375

19 Kraemer WJ, Ratamess NA. Fundamentals of resistance training: progression and exercise prescription. Med Sci Sports Exerc 2004; 36: 674-688

20 López-Segovia M, Palao Andrés JM, González-Badillo JJ. Effect of 4 months of training on aerobic power, strength, and acceleration in two under-19 soccer teams. J Strength Cond Res 2010; 24: 2705-2714

21 Lyttle AD, Wilson GJ, Ostrowski KJ. Enhancing performance: maximal power versus combined weights and plyometrics training. J Strength Cond Res 1996; 10: 173-179

22 Markovic G, Jukic I, Milanovic D, Metikos D. Effects of sprint and plyometric training on muscle function and athletic performance. J Strength Cond Res 2007; 21: 543-549

23 Mero A, Komi PV, Gregor RJ. Biomechanics of sprint running. A review. Sports Med 1992; 13: 376-392

24 Sáez de Villarreal E, Requena B, Izquierdo M, Gonzalez-Badillo JJ. Enhancing sprint and strength performance: Combined versus maximal power, traditional heavy-resistance and plyometric training. J Sci Med Sport 2013; 16: 146-150

25 Sale DG. Neural adaptation to resistance training. Med Sci Sports Exerc 1988; 20: S135-S145 
26 Sanchez-Medina L, Perez CE, Gonzalez-Badillo JJ. Importance of the propulsive phase in strength assessment. Int J Sports Med 2010; 31: 123-129

27 Sleivert G, Taingahue M. The relationship between maximal jumpsquat power and sprint acceleration in athletes. Eur J Appl Physiol 2004; 91: 46-52

28 Sleivert GG, Backus RD, Wenger HA. The influence of a strength-sprint training sequence on multi-joint power output. Med Sci Sports Exerc 1995; 27: 1655-1665

29 Tillin NA, Bishop D. Factors modulating post-activation potentiation and its effect on performance of subsequent explosive activities. Sports Med 2009; 39: 147-166
30 Wenzel RR, Perfetto EM. The effect of speed versus non-speed training in power development. J Strength Cond Res 1992; 6: 82-87

31 Wilson GJ, Newton RU, Murphy AJ, Humphries BJ. The optimal training load for the development of dynamic athletic performance. Med Sci Sports Exerc 1993; 25: 1279-1286

32 Young $W$, McLean B, Ardagna J. Relationship between strength qualities and sprinting performance. J Sports Med Phys Fitness 1995; 35: 13-19

33 Young WB. Transfer of strength and power training to sports performance. Inter J Sports Physiol Perform 2006; 1: 74-83 